\title{
Expression of human Piwi-like genes is associated with prognosis for soft tissue sarcoma patients
}

Thomas Greither ${ }^{1 \dagger}$, Franziska Koser ${ }^{2 \dagger}$, Matthias Kappler ${ }^{2}$, Matthias Bache ${ }^{3}$, Christine Lautenschläger ${ }^{4}$, Steffen Göbel ${ }^{5}$, Hans-Jürgen Holzhausen ${ }^{6}$, Sven Wach ${ }^{7,8}$, Peter Würl $^{9}$ and Helge Taubert ${ }^{7,8,10^{*}}$

\begin{abstract}
Background: Argonaute genes are essential for RNA interference, stem cell maintenance and differentiation. The Piwi-like genes, a subclass of the Argonaute genes, are expressed mainly in the germline. These genes may be re-expressed in tumors, and expression of the Piwi-like genes is associated with prognosis in several types of tumors.

Methods: We measured the expression of Piwi-like mRNAs (Piwi-like 2-4) in 125 soft tissue sarcoma (STS) samples by qPCRs. Statistical tests were applied to study the correlation of expression levels with tumorspecific survival for STS patients.

Results: In multivariate Cox's regression analyses, we showed that low Piwi-like 2 and Piwi-like 4 mRNA expression were significantly associated with a worse prognosis ( $R R=1.87 ; p=0.032$ and $R R=1.82 ; p=0.039$ ). Low expression of both genes was associated with a 2.58-fold increased risk of tumor-related death $(p=0.01)$. Piwi-like 4 and combined Piwi-like 2 and $4 \mathrm{mRNA}$ levels correlated significantly with prognosis $(\mathrm{RR}=3.53$; $p=0.002$ and $R R=5.23 ; p=0.004$ ) only for female but not for male patients. However, combined low Piwi-like 2 and 3 transcript levels were associated with worse survival $(R R=5.90 ; p=0.02)$ for male patients.

Conclusions: In this study, we identified a significant association between the expression of Piwi-like 2 and 4 mRNAs and the tumor-specific survival of soft tissue sarcoma patients. Furthermore, a connection between sex and the impact of Piwi-like mRNA expressions on STS patients' prognosis was shown for the first time.
\end{abstract}

\section{Background}

The Piwi (ㅁ-element-induced wimpy testis) family is a subclass of the Argonaute gene/protein family characterized by their homology and the occurrence of PAZ and Piwi domains [1,2]. PIWI proteins play important roles in stem cell self-renewal, spermatogenesis, transposon and RNA silencing, translational regulation, and chromatin remodeling in various organisms [3]. Cox and coworkers identified the first Piwi gene in Drosophila [4]. Piwi is required for the asymmetric division of germ-line stem cells (GSCs) to produce and to maintain a daughter GSC (stem cell self-renewal). In addition, homologues of the Piwi gene have been identified in

\footnotetext{
* Correspondence: helge.taubert@uk-erlangen.de

${ }^{\dagger}$ Equal contributors

${ }^{7}$ Div. Molecular Urology, FAU Erlangen-Nürnberg, University Clinic of Urology, Erlangen, Germany

${ }^{8}$ Nikolaus-Fiebiger-Center for Molecular Medicine, FAU Erlangen-Nürnberg,

Erlangen, Germany

Full list of author information is available at the end of the article
}

Caenorhabditis elegans, Arabidopsis and humans, but not in bacteria or yeast, suggesting that Piwi has a stem cell-related function existing only in multicellular organisms. Piwi-like genes also play a role in adult somatic stem cells, such as human hematopoietic stem cells and mouse mesenchymal stem cells [5,6]. Four members of the human Piwi gene family, Piwi-like 1 (Hiwi, Piwil1), Piwi-like 2 (Hili, Piwil2), Piwi-like 3 (Piwil3) and Piwilike 4 (Hiwi2, Piwil4), have been described so far [7]. The genes have been mapped to different chromosomal regions. Piwi-like 1 and Piwi-like 2 are located on chromosome 12 (12q23-12q24.33) and chromosome 8 (8p21). Piwi-like 3 and Piwi-like 4 have been mapped to chromosome 22 (22q11.2) and chromosome 11 (11q12).

An increasing number of publications have demonstrated that members of the Piwi family may be reexpressed in malignant tumors. Expression of these genes may correlate with tumor behavior and patient prognosis. Elevated protein expression of PIWIL1 is 
associated with a poor prognosis in seminoma, gastric cancer, esophageal cancer and glioma [8-11]. PIWIL2 protein may be detected in various stages of cervical squamous cell carcinoma and breast adenocarcinoma, as well as in metaplastic epithelial cells and histologically normal-appearing tissues adjacent to breast and cervical tumors [12-14]. Additionally, high levels of PIWIL2, PIWIL3 and PIWIL4 proteins are correlated with an elevated risk of colon cancer [15]. Li and coworkers also showed that increased PIWIL4 protein levels are significantly associated with the risk of metastasis and prognosis in colon cancer patients [15].

Protein levels and mRNA levels are not necessarily correlated [16]. Reasons for this could be different mRNA stability, mRNA degradation, and posttranscriptional regulation mechanisms. There are regulatory layers of the transcriptome in which RNA-binding proteins (RBPs), noncoding regulatory RNAs (ncRNAs) and messenger RNAs (mRNAs) can interact [17].

However, there have been comparatively few studies evaluating the impact of Piwi-like 1-4 mRNA expression in human cancers. In patients with gastric cancer and soft tissue sarcoma (STS) and in male pancreatic carcinoma patients, the levels of mRNA expression of Piwi-like 1 are correlated with prognosis $[9,18,19]$. Expression of the Piwi-like 2 gene has been detected in many different human tumors, including prostate, breast, gastrointestinal, ovarian and endometrial cancers [20]. However, no data have been published about Piwilike 3 and Piwi-like 4 mRNA expression levels in human tumors. A search in the Oncomine database revealed an expression of Piwi-like 3 in carcinomas of the breast, colon, ovary and brain and for Piwi-like 4 in carcinomas of the breast, liver and brain. In this study, we investigated Piwi-like mRNA expression in patients with STS. We attempted to correlate Piwi-like mRNA levels with clinical factors such as tumor size and with tumorspecific survival. We also performed a sex-specific analysis of the prognostic impact of Piwi-like mRNA expression in patients with STS.

\section{Methods}

\section{Patients}

In this study, tumor tissue samples of 125 patients with STS were analyzed. All patients underwent surgical resection in the Department of Surgery, Martin-LutherUniversity Halle-Wittenberg and the Department of Surgery 1, University of Leipzig, Germany. The cohort has been described in previous studies [21]. All diagnoses were verified by an experienced pathologist $(\mathrm{HJH})$ according to the UICC system. All patients gave written informed consent. The study was approved by the Ethic Committee of the Medical Faculty of the Martin-LutherUniversity Halle-Wittenberg and it was performed in compliance with the Helsinki Declaration. Median patient age at the time of surgery was 58 years (range 1487 years). Median follow-up time was 32 months (range 2-201 months after primary tumor resection). Forty-nine patients experienced locoregional recurrence, 10 patients developed distant metastases and 61 patients died during the observation time. All tumor samples were collected before radio- or chemotherapy. For clinical and histopathologic parameters, please refer to Table 1.

\section{RNA isolation}

Ten to twenty tumor tissue slices $(30 \mu \mathrm{m})$ were used for RNA isolation with Trizol reagent according to the manufacturer's protocol (Invitrogen, Karlsruhe, Germany). Briefly, RNA was extracted with phenol/chloroform and precipitated by isopropanol. Any remaining DNA traces were removed by DNAse I digestion (Qiagen, Hilden, Germany). The remaining pellet was washed twice in ice-cold ethanol and resuspended in $30 \mu \mathrm{l}$ of RNAse-free water. RNA concentration was assessed with a Nanodrop ND-1000 Spectrophotometer (Thermo Scientific, Karlsruhe, Germany). RNA was stored at $-80{ }^{\circ} \mathrm{C}$.

\section{cDNA synthesis}

Two micrograms of RNA were used for cDNA synthesis. cDNA was synthesized with the RevertAid H Minus First strand cDNA Synthesis Kit according to the manufacturer's protocol (Fermentas, St. Leon-Rot, Germany).

\section{qPCR}

Piwi-like gene expression was measured using TaqMan Gene expression assays (Piwi-like 2: Hs01032719; Piwilike 3: Hs00908837; Piwi-like 4: Hs00895218) according to the manufacturer's protocol (Applied Biosystems, Darmstadt, Germany). The recognition sites of primers within the Piwi-like mRNAs are given in Additional file 1: Figure S1. Quantitative RT-PCR reactions were performed with the HotStart-Taq Polymerase Kit (Qiagen, Hilden, Germany) in a real-time cycler (LTF, Wasserburg; Germany). HPRT (hypoxanthine phosphoribosyl transferase) expression was measured with the following primers (HPRT fw: 5' -TTGCTGACCTGCTGGATTAC3'; rw: 5'-CTTGCG ACCTTGACCATCTT-3') using Maxima SYBR-Green qPCR Master Mix (Fermentas, St. Leon-Rot, Germany) and served as reference gene. All measurements were carried out from the same cDNA aliquot within a short time period to ensure comparable conditions. Gene expression was normalized to HPRT mRNA expression. Quantification was performed using self-established plasmid standards for Piwi-like 2, 3 and 4 and HPRT in the range of $10^{4}-10^{8}$ copies/ $\mu \mathrm{l}$. Relative mRNA expression ratios (copies of transcript per fg HPRT) were used for subsequent statistical analyses. 
Table 1 The histopathologic, clinical and Piwi-like mRNA expression data of STS patients

\begin{tabular}{|c|c|c|c|c|c|c|c|}
\hline \multirow{2}{*}{$\begin{array}{l}\text { Patients' } \\
\text { characteristics }\end{array}$} & \multirow{2}{*}{$\begin{array}{l}\text { No. of } \\
\text { cases }\end{array}$} & \multicolumn{2}{|c|}{ Piwi-like 2} & \multicolumn{2}{|c|}{ Piwi-like 3} & \multicolumn{2}{|c|}{ Piwi-like 4} \\
\hline & & low & high & low & high & low & high \\
\hline Total & 125 & 62 & 63 & 62 & 63 & 62 & 63 \\
\hline \multicolumn{8}{|l|}{ Sex } \\
\hline Male & 57 & 29 & 28 & 26 & 31 & 27 & 30 \\
\hline Female & 68 & 33 & 35 & 36 & 32 & 35 & 33 \\
\hline \multicolumn{8}{|c|}{ Histological subtype } \\
\hline LS & 28 & 10 & 18 & 14 & 14 & 11 & 17 \\
\hline $\mathrm{MFH}$ & 31 & 12 & 19 & 17 & 14 & 19 & 12 \\
\hline FS & 7 & 4 & 3 & 5 & 2 & 3 & 4 \\
\hline RMS & 8 & 5 & 3 & 2 & 6 & 5 & 3 \\
\hline LMS & 21 & 14 & 7 & 9 & 12 & 9 & 12 \\
\hline NS & 12 & 6 & 6 & 4 & 8 & 6 & 6 \\
\hline Syn & 10 & 5 & 5 & 7 & 3 & 5 & 5 \\
\hline Other & 8 & 6 & 2 & 4 & 4 & 4 & 4 \\
\hline
\end{tabular}

\section{Tumor size}

$\mathrm{T} 1$

$\mathrm{T} 2$

Tumor grade

$\begin{array}{lccccccc}\mid & 19 & 7 & 12 & 7 & 12 & 5 & 14 \\ \| & 58 & 30 & 28 & 29 & 29 & 31 & 27 \\ || & 48 & 25 & 23 & 26 & 22 & 26 & 22\end{array}$

Tumor stage

\begin{tabular}{lccccccc} 
I II & 16 & 6 & 10 & 7 & 9 & 5 & 11 \\
III & 57 & 28 & 29 & 29 & 28 & 29 & 28 \\
IV & 40 & 21 & 19 & 21 & 19 & 22 & 18 \\
Complete resection & 12 & 7 & 5 & 5 & 7 & 6 & 6 \\
Radical (R0) & 87 & 44 & 43 & 44 & 43 & 42 & 45 \\
Not radical (R1) & 38 & 18 & 20 & 18 & 20 & 20 & 18 \\
ocation & & & & & & & \\
Extremities & 80 & 36 & 44 & 41 & 39 & 41 & 39 \\
Trunk wall & 12 & 9 & 3 & 8 & 4 & 6 & 6 \\
Head/neck & 4 & 2 & 2 & 1 & 3 & 4 & 0 \\
Abdomen/ & 27 & 14 & 13 & 12 & 15 & 11 & 16 \\
retroperitoneum & & & & & & & \\
Multiple locations & 2 & 1 & 1 & 0 & 2 & 0 & 2 \\
Patient status & & & & & & & \\
Alive & 64 & 26 & 38 & 31 & 33 & 30 & 34 \\
Dead & 61 & 36 & 25 & 31 & 30 & 32 & 29 \\
\hline
\end{tabular}

Abbreviations: No-number of cases, $\mathrm{LS}$-liposarcoma, $\mathrm{MFH}$-malignant fibrous histiocytoma, FS-fibrosarcoma, RMS-rhabdomyosarcoma, LMS-leiomyosarcoma, NS-neuronal sarcoma, Syn-synovial sarcoma.

${ }^{1} \mathrm{~T} 1 \leq 5 \mathrm{~cm}, \mathrm{~T} 2>5 \mathrm{~cm}$.

\section{Statistical analyses}

Bivariate correlation analyses were performed by Spearman rank correlations $\left(\mathrm{r}_{\mathrm{s}}\right)$. Kaplan-Meier and multivariate Cox's regression analyses were performed to analyze the correlation of Piwi-like 2-4 mRNA expression levels with tumor-specific survival. All statistical analyses were conducted with PASW 18 software (IBM SPSS, Chicago, IL, USA). P-values $<0.05$ were considered significant.

\section{Results}

Expression of Piwi-like 2-4 mRNAs and their association with clinical, histopathologic and molecular parameters Piwi-like 2, Piwi-like 3 and Piwi-like 4 mRNA expression levels were measured in tissue samples from 125 STS patients. Cut-off values were set according to the median value for each gene (Piwi-like 2: 7.583 copies/fg HPRT (range: 0.073-532.45), Piwi-like 3: 0.05 copies/ fg HPRT (range: 0-52.82) and Piwi-like 4: 1.754 copies/ fg HPRT (range: 0-22.89)).

In addition we studied the Piwi-like 2, Piwi-like 3 and Piwi-like 4 mRNA expression levels in normal tissue samples adjacent to tumor tissues from 22 out of the 125 STS patients. We detected median mRNA expression levels for Piwi-like 2: 0.5 copies/fg HPRT (range 0.04-24.84), for Piwi-like 3: 0.0 copies/fg HPRT (range 0-5), and for Piwi-like 4: 0.28 copies/fg HPRT (range 039.5). The Piwi-like 2, Piwi-like 3 and Piwi-like 4 mRNA expression levels are higher in the tumor tissues compared to those in the normal tumor adjacent tissues. But they are not correlated with each other (Spearman-Rho test) and the median values of their differences are unequal ( $\mathrm{p}<0.05$; Wilcoxon test).

We performed a bivariate linear correlation analysis (Spearman-Rho-test) to examine whether the mRNA expression levels of individual Piwi-like genes were correlated with the mRNA expression levels of the other Piwi-like genes in the tumor tissues. The expression levels of mRNA for Piwi-like 2 and Piwi-like 4 were highly significantly correlated $\left(\mathrm{r}_{\mathrm{s}}=0.36 ; \mathrm{p}=0.00003\right)$, whereas no significant correlation was detected for either mRNA with Piwi-like 3 in the tumor tissues.

Bivariate linear correlation analysis was also performed to analyze the relationship of Piwi-like mRNA expression with clinical factors. The mRNA levels of all Piwilike genes studied were positively correlated to tumor size (Piwi-like 2: $\mathrm{r}_{\mathrm{s}}=0.21 ; \mathrm{p}=0.018$; Piwi-like 3: $\mathrm{r}_{\mathrm{s}}=0.20$; $\mathrm{p}=0.024 ;$ and Piwi-like 4: $\mathrm{r}_{\mathrm{s}}=0.18 ; \mathrm{p}=0.041$ ), Next, we investigated the correlation of Piwi-like 2-4 mRNAs with other stem cell-associated genes (Nanog, Oct3/4 and survivin). Piwi-like 2 mRNA expression was inversely correlated with transcript levels of Oct3/4 and Nanog in our STS cohort $\left(r_{s}=-0.31 ; p=0.002\right.$ and $r_{s}=$ $-0.23 ; \mathrm{p}=0.029$, respectively) but was positively correlated with the splice variant $2 \mathrm{~B}$ of the survivin gene $\left(\mathrm{r}_{\mathrm{s}}=\right.$ 
0.20; $\mathrm{p}=0.048$ ). Piwi-like 3 mRNA expression was also negatively correlated with Nanog transcript levels $\left(\mathrm{r}_{\mathrm{s}}=\right.$ -0.24; $\mathrm{p}=0.02$ ). Piwi-like $4 \mathrm{mRNA}$ levels were negatively associated with the expression of the splice variant Delta 3 of the survivin gene $\left(\mathrm{r}_{\mathrm{s}}=-0.18 ; \mathrm{p}=0.047\right.$; Additional file 2: Table S1).

\section{Association of the Piwi-like 2-4 mRNA expression level with tumor-specific survival for all STS patients}

Multivariate Cox's regression analyses (adjusted for clinical parameters including resection type, tumor stage, tumor location and tumor type) were performed to study the effect of the mRNA expression level of the three Piwi-like genes on tumor-specific survival. For Piwi-like 2, low mRNA expression was significantly associated with a worse prognosis $(\mathrm{RR}=1.87,95 \% \mathrm{CI}$ : $1.06-$ 3.32; $\mathrm{p}=0.032$ ). Low Piwi-like 4 mRNA expression also correlated significantly with decreased tumor-specific survival $(\mathrm{RR}=1.82$, 95\% CI: 1.03-3.21; $\mathrm{p}=0.039)$. Piwilike 3 expression was not significantly associated with the prognosis of STS patients $(\mathrm{RR}=1.33$, 95\% CI: $0.75-$ $2.3 ; \mathrm{p}=0.329)$.

Next, we studied the combined expression of the Piwilike $2-4$ and their correlation with tumor-specific survival. Patients expressing low levels of either Piwi-like 2/ Piwi-like 3 or of Piwi-like 2/Piwi-like 4 had a significantly increased risk of tumor-related death compared with patients with a high expression level of the Piwi-like mRNAs $(\mathrm{RR}=2.10,95 \% \mathrm{CI}: 1.01-4.40 ; \mathrm{p}=0.048$ and

Table 2 Multivariate Cox's regression analyses on the impact of Piwi-like 2, -3 and -4 mRNA expression on STS patients' survival

\begin{tabular}{lccc}
\hline & Piwi-like 2 & Piwi-like 3 & Piwi-like 4 \\
\hline Relative risk (RR) & $\mathbf{1 . 8 7}$ & 1.33 & $\mathbf{1 . 8 2}$ \\
$95 \% \mathrm{Cl}$ & $1.06-3.32$ & $0.75-2.3$ & $1.03-3.21$ \\
p-value & $\mathbf{0 . 0 3 2}$ & 0.329 & $\mathbf{0 . 0 3 9}$ \\
n low & 62 & 62 & 62 \\
n high & 63 & 63 & 63 \\
& Combination & Combination & \\
\hline Relative risk (RR) & $\mathbf{2 . 5 8}$ & $\mathbf{4 . 0 1}$ & \\
$95 \%$ Cl & $1.26-5.29$ & $1.61-10.01$ & \\
p-value & $\mathbf{0 . 0 1}$ & $\mathbf{0 . 0 0 3}$ & \\
n all low & 39 & 21 & \\
n one gene elevated & 46 & 43 & \\
n two genes elevated & - & 37 & \\
n all genes elevated & 40 & 24 & \\
\hline
\end{tabular}

Significant $p$-values and relative risks are marked in bold face ( $p$-values $<0.05$ were considered significant).
$\mathrm{RR}=2.58, \quad 95 \% \quad \mathrm{CI}: \quad 1.26-5.29 ; \mathrm{p}=0.01$, respectively; Table 2 ).

Association of the Piwi-like 2-4 mRNA expression level with tumor-specific survival in a sex- specific manner for STS patients

We performed separate analyses of the association of Piwi-like 2-4 expression in male and female patients (Additional file 3: Figure S2). Female patients with a low level of Piwi-like 4 mRNA expression in their tumors had a 3.53-fold significantly increased risk of tumorrelated death (95\% CI: 1.56-8.0; $\mathrm{p}=0.002)$. Furthermore, in females, a trend for increased risk of tumor-related death was seen in patients with low levels of Piwi-like 2 expression ( $R R=1.88,95 \% \mathrm{CI}$ : 0.87-4.07). However, this result was not statistically significant $(\mathrm{p}=0.106)$. Male patients with low levels of Piwi-like 2 or Piwi-like 3 had a 2.76-fold and a 2.59-fold increased risk of tumorrelated death. However, this result was also not statistically significant (Table 3 ).

Finally, we analyzed the combined expression of the Piwi-like 2-4 genes and their correlation with tumorspecific survival in a sex-specific manner and observed that different expression profiles were significantly correlated with survival in male and female patients. For male patients, decreased expression of Piwi-like 2/ Piwi-like 3 was correlated with a 5.9-fold increase in the risk of tumor-related death (95\% CI: 1.33-26.23; $\mathrm{p}=0.02)$. In female patients, decreased Piwi-like 2/ Piwi-like 4 expression was correlated with a 5.23-fold increase in the risk of tumor-related death $(95 \% \mathrm{CI}$ : 1.67-16.32; $\mathrm{p}=0.004$; Table 3 Figure 1). The results revealed that the combined expression of Piwi-like genes is correlated with tumor-specific survival in a sex-specific manner.

\section{Discussion}

Previously we found that elevated levels of Piwi-like 1 in STS and high as well as low levels of Piwi-like 1 in pancreatic adenocarcinomas were significantly associated with worse patient's survival. $[18,19]$. In our study, the levels of Piwi-like 2-4 mRNA in STS were analyzed and correlated with each other, with clinical and histopathologic parameters and with tumor-specific survival. We found a significant correlation between tumor-specific survival and Piwi-like 2 and Piwi-like 4 mRNA expression levels, but not with Piwi-like 3 gene expression. There were correlations between the mRNA expressions of the Piwi-like genes and other stem cell-associated genes, such as Nanog, Oct3/ 4 and survivin. Surprisingly, a low expression of Piwi-like 2 or Piwi-like 3 was significantly correlated with a high expression level of Nanog and Piwi-like-2 in addition with an increased transcript level of Oct $3 / 4$, but with a decreased level of the survivin 2B splice variant. Furthermore, low 


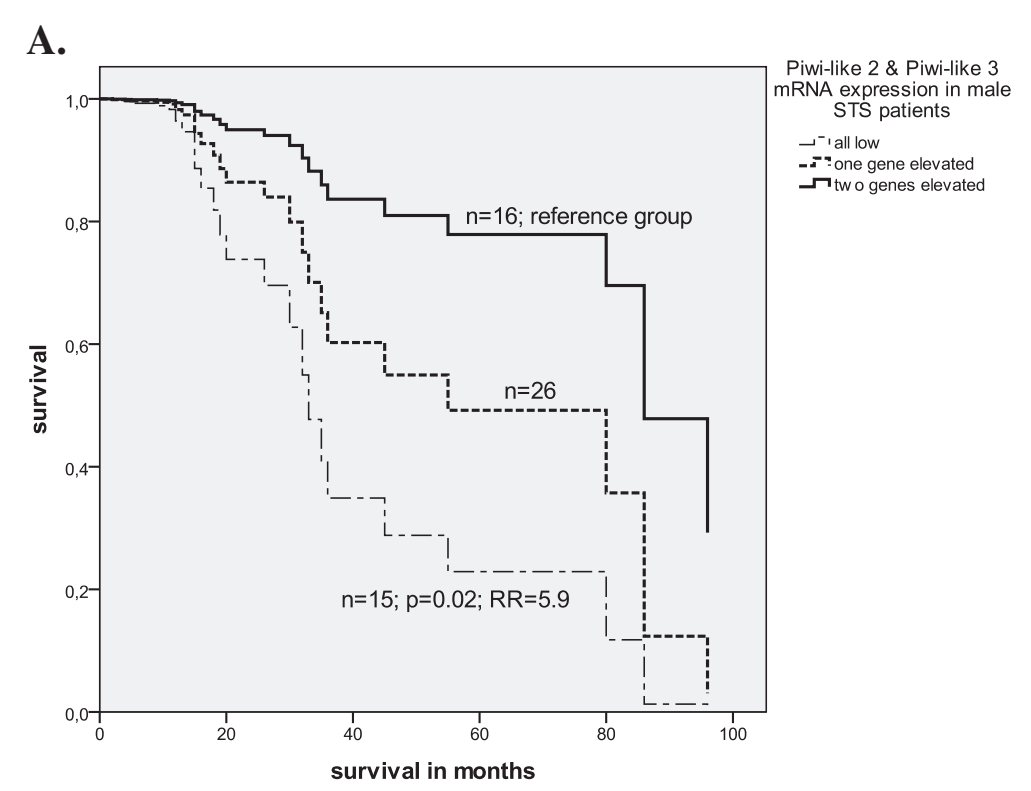

B.

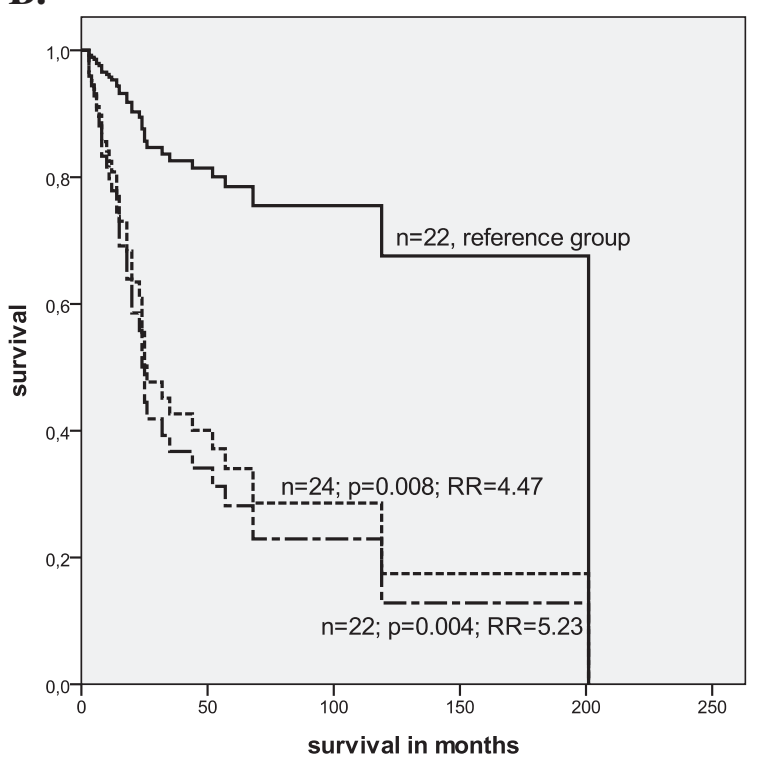

Piwi-like 2 \& Piwi-like 4 mRNA expression in female STS patients

$\rightarrow$-iall low

$-\because$ one gene elevated $\neg$ two genes elevated

Figure 1 Multivariate Cox's regression analyses: A. Combined expression of Piwi-like 2 and 3 in male STS patients and B. combined Piwi-like 2 and -4 expression in female STS patients and their correlation with tumor-specific survival.

Piwi-like 4 mRNA expression was correlated with a high level of the survivin Delta 3 splice variant. However, the survivin $2 \mathrm{~B}$ splice variant is considered to be a proapoptotic protein, whereas the survivin Delta 3 splice variant has an anti-apoptotic function [22]. PIWIL2 protein may inhibit apoptosis via activation of Stat3/Bcl-X signaling [20].

A somewhat surprising result of our study was that a low mRNA expression level of all three Piwi-like genes was correlated with a poor prognosis, although higher protein levels have been reported to be associated with a poor survival [8-11]. There are several possible explanations for this phenomenon. Low mRNA transcription levels may characterize more aggressive tumors. For example, low mRNA levels for the oncogenes $m d m 2$ and $c$-myc have been correlated with a poor prognosis of patients with STS and squamous carcinomas of the tongue, respectively $[23,24]$. Another possibility is that there could be a negative autoregulatory feedback loop between protein and RNA levels in Piwi-like genes. Such a feedback loop has been described for other genes, for example for Snail1. Snail1 is a transcriptional repressor that binds to its own promoter 
Table 3 Sex-specific association between Piwi-like 2-4 mRNA expression and STS patient survival

\begin{tabular}{|c|c|c|c|c|c|c|c|c|}
\hline & \multicolumn{3}{|c|}{ Female patients } & & \multicolumn{3}{|c|}{ Male patients } & \\
\hline & Piwi-like 2 & Piwi-like 3 & Piwi-like 4 & & Piwi-like 2 & Piwi-like 3 & Piwi-like 4 & \\
\hline Relative risk (RR) & 1.88 & 1.13 & 3.53 & & 2.76 & 2.59 & 1.10 & \\
\hline $95 \% \mathrm{Cl}$ & $0.87-4.07$ & $0.51-2.52$ & $1.56-8.00$ & & $0.95-8.04$ & $0.81-8.33$ & $0.36-3.31$ & \\
\hline p-value & 0.106 & 0.757 & 0.002 & & 0.062 & 0.11 & 0.87 & \\
\hline n low & 34 & 34 & 34 & & 28 & 28 & 28 & \\
\hline \multirow[t]{2}{*}{$\mathrm{n}$ high } & 34 & 34 & 34 & & 29 & 29 & 29 & \\
\hline & $\begin{array}{c}\text { Combination } \\
\text { Piwi-like } 2 \text { and }-4 \\
\end{array}$ & $\begin{array}{c}\text { Relative risk } \\
\text { (RR) }\end{array}$ & $\mathbf{9 5} \% \mathrm{Cl}$ & p-value & $\begin{array}{c}\text { Combination } \\
\text { Piwi-like } 2 \text { and }-3 \\
\end{array}$ & $\begin{array}{c}\text { Relative risk } \\
\text { (RR) }\end{array}$ & $\mathbf{9 5} \% \mathrm{Cl}$ & p-value \\
\hline $\mathrm{n}$ all low & 22 & 5.23 & $1.67-16.32$ & 0.004 & 15 & 5.90 & $1.33-26.23$ & 0.02 \\
\hline n one gene elevated & 24 & 4.47 & $1.47-13.61$ & 0.008 & 26 & 2.84 & $0.77-10.41$ & 0.12 \\
\hline n two genes elevated & 22 & reference & & & 16 & reference & & \\
\hline
\end{tabular}

Significant $p$-values and relative risks are marked in bold face ( $p$-values $<0.05$ were considered significant).

and controls its expression [25]. Analogously, one may speculate that Piwi-like proteins, as the main effector component of the RNA-induced silencing complex (RISC), may regulate their own expression by posttranscriptional gene silencing via an unknown small RNA binding partner. Furthermore, different alternative transcripts leading to shortened protein products of PIWIL2 have been described recently [12]. The predominant form, PL2L60, is mainly expressed in tumor cells and promotes cell survival and proliferation of a human breast cancer cell line (MDA-MB-231), possibly by the upregulation of $\mathrm{Bcl} 2$ and Stat3. Because our primers targeted the $5^{\prime}$ end of the different mRNA transcripts for a better discrimination between the homologous genes, we were not able to measure the shortened transcript. Further studies are needed to determine if shortened alternative mRNA transcripts and protein isoforms for Piwi-like 3 and Piwi-like 4 also exist. Additionally, shorter transcripts and/or their protein products could decrease the levels of their full-length transcripts.

Piwi-like proteins bind exclusively to Piwi-interacting RNA (piRNA), a class of small RNAs that differ structurally from the classic siRNA and miRNA in several ways, including length (24-30 nt instead of 18-23 nt), the carriage of a $2^{\prime} \mathrm{O}$-methyl modification at the 3 ' end and their low conservation among even closely related species [26-28]. piRNAs are transcribed from a limited set of clusters located in pericentromeric or telomeric heterochromatic regions by an as yet unknown mechanism [29]. Their maturation is involved in a set of degradation steps involving transposon transcripts. Uncontrolled transposon activation in Piwi gene mutants has been observed in Drosophila and in mice [30,31], which points to a role of Piwi-like genes in transposon control during spermatogenesis. However, the mechanisms and consequences of Piwi-like gene re-initiation in tumors are not yet fully understood. Given our observation that a low mRNA expression of Piwi-like genes is correlated with increased tumor size and worse survival, one may speculate that a decrease in the mRNA of Piwi-like genes can derepress transposon activity and enhance tumor cell selection to a more proliferative, active and aggressive phenotype.

PIWI proteins appear to have sex-specific functions, especially in vertebrate male germ cell maturation [30-32]. We were able to show for the first time a sex-specific effect of Piwi-like gene expression on the survival of tumor patients. The presence of androgen and estrogen receptors has been reported in soft tissue sarcomas [33]. An in-silico search for binding sites for sex-steroid receptors in the putative promoter regions of the Piwi-like genes showed an androgen receptor binding site in the Piwi-like 2 gene promoter (unpublished results). However, the transcriptional activation of the Piwi-like genes may also be initiated indirectly by transcription factors regulated by sex-steroid binding factors. This question should be addressed in further studies.

\section{Conclusions}

In conclusion, a correlation of Piwi-like 2-4 mRNA expression with tumor size and of Piwi-like 2 and Piwi-like 4 transcript levels with tumor-related death was found for STS patients. Additionally, there was a sex-specific association of the combination of low mRNA transcript levels for Piwi-like 2/-3 and Piwi-like 2/-4 with tumorspecific survival in male and in female STS patients, respectively. A low mRNA expression level for Piwi-like 2-4 genes defines a significantly increased risk for tumor-related death and may have potential as a predictor of survival for both all STS patients and in a sexspecific manner. 


\section{Additional files}

Additional file 1: Figure S1 Binding sites of the commercial TaqMan primer in the different Piwi-like genes.

Additional file 2: Table S1 Spearman-Rho bivariate linear correlation analyses: Significant correlations of Piwi-like 2-4 mRNA expression with tumor size and gene expression levels of other stem cell-associated genes in our cohort of STS.

Additional file 3: Figure S2 Distribution of Piwi-like 2, -3, and -4 mRNA expression separated by gender.

\section{Competing interests}

The authors report no potential conflicts of interest.

\section{Authors' contributions}

TG designed the study, analyzed the data and drafted the manuscript. FK performed experimental procedures, carried out molecular biological studies and analyzed the data, MKa and MBa aided in study design, analyzed the data and reviewed the manuscript. PW treated the patients, collected tumor/ normal tissues and clinical data and participated in the study design, $C L$ and SG performed and reviewed statistical analysis, HJH performed histopathological evaluation and reevaluation of sarcoma tissues, SW carried out molecular biological studies and analyzed the data, HT designed the study, analyzed the data and drafted the manuscript. All authors read and approved the final manuscript.

\section{Acknowledgements}

H.T.'s work was supported by the Deutsche Krebshilfe (No. 107590) and was associated with the German Sarcoma Study Group K.O.S.A.R. T.G.'s work was supported by a grant of the Wilhelm-Roux program (FKZ 24/15). We would like to thank the American Journal Experts for language editing of our manuscript.

\section{Author details}

${ }^{1}$ Center for Reproductive Medicine and Andrology, Martin-Luther-University Halle-Wittenberg, Halle, Germany. ${ }^{2}$ Department of Oral and Maxillofacial Plastic Surgery, Martin-Luther-University Halle-Wittenberg, Halle, Germany. ${ }^{3}$ Department of Radiotherapy, Martin-Luther-University Halle-Wittenberg, Halle, Germany. ${ }^{4}$ Institute of Medical Biometry and Informatics, Martin-Luther-University Halle-Wittenberg, Halle, Germany. ${ }^{5}$ Institute of Transfusion Medicine, Martin-Luther-University Halle-Wittenberg, Halle, Germany. ${ }^{6}$ Institute of Pathology, Martin-Luther-University Halle-Wittenberg, Halle, Germany. ${ }^{7}$ Div. Molecular Urology, FAU Erlangen-Nürnberg, University Clinic of Urology, Erlangen, Germany. ${ }^{8}$ Nikolaus-Fiebiger-Center for Molecular Medicine, FAU Erlangen-Nürnberg, Erlangen, Germany. ${ }^{9}$ Department of General and Visceral Surgery, Diakoniekrankenhaus Halle, Halle, Germany, ${ }^{10}$ Klinik für Urologie und NFZ, FAU Erlangen, Glückstr. 6, D-91054 Erlangen, Germany.

Received: 22 November 2011 Accepted: 15 May 2012

Published: 29 June 2012

\section{References}

1. Cerutti L, Mian N, Bateman A: Domains in gene silencing and cell differentiation proteins: the novel PAZ domain and redefinition of the Piwi domain. Trends Biochem Sci 2000, 25:481-482

2. Carmell MA, Xuan Z, Zhang MQ, Hannon GJ: The Argonaute family: tentacles that reach into RNAi, developmental control, stem cell maintenance, and tumorigenesis. Genes Dev 2002, 16:2733-2742.

3. Wang QE, Han C, Milum K, Wani AA: Stem cell protein Piwil2 modulates chromatin modifications upon cisplatin treatment. Mutat Res 2011, 708:59-68.

4. Cox DN, Chao A, Baker J, Chang L, Qiao D, Lin H: A novel class of evolutionarily conserved genes defined by piwi are essential for stem cell self-renewal. Genes Dev 1998, 12:3715-3727.

5. Sharma AK, Nelson MC, Brandt JE, Wessman M, Mahmud N, Weller KP, Hoffman R: Human CD34(+) stem cells express the hiwi gene, a human homologue of the Drosophila gene piwi. Blood 2001, 97:426-434.
6. Wu Q, Ma Q, Shehadeh LA, Wilson A, Xia L, Yu H, Webster KA: Expression of the Argonaute protein PiwiL2 and piRNAs in adult mouse mesenchymal stem cells. Biochem Biophys Res Commun 2010, 396:915-920.

7. Sasaki T, Shiohama A, Minoshima S, Shimizu N: Identification of eight members of the Argonaute family in the human genome. Genomics 2003, 82:323-330.

8. Qiao D, Zeeman AM, Deng W, Looijenga LH, Lin H: Molecular characterization of hiwi, a human member of the piwi gene family whose overexpression is correlated to seminomas. Oncogene 2002, 21:3988-3999.

9. Liu X, Sun Y, Guo J, Ma H, Li J, Dong B, Jin G, Zhang J, Wu J, Meng L, Shou $C$ : Expression of hiwi gene in human gastric cancer was associated with proliferation of cancer cells. Int J Cancer 2006, 118:1922-1929.

10. He W, Wang Z, Wang Q, Fan Q, Shou C, Wang J, Giercksky KE, Nesland JM, Suo Z: Expression of HIWI in human esophageal squamous cell carcinoma is significantly associated with poorer prognosis. BMC Cancer 2009, 9:426.

11. Sun G, Wang Y, Sun L, Luo H, Liu N, Fu Z, You Y: Clinical significance of Hiwi gene expression in gliomas. Brain Res 2011, 1373:183-188.

12. Ye Y, Yin DT, Chen L, Zhou Q, Shen R, He G, Yan Q, Tong Z, Issekutz AC, Shapiro CL, Barsky SH, Lin H, Li YY, Gao JX: Identification of Piwil2-like (PL2L) proteins that promote tumorigenesis. PLoS One 2010, 5:e13406.

13. He G, Chen L, Ye Y, Xiao Y, Hua K, Jarjoura D, Nakano T, Barsky SH, Shen R, Gao JX: Piwil2 expressed in various stages of cervical neoplasia is a potential complementary marker for p16. Am J Transl Res 2010, 2: 156-169.

14. Liu JJ, Shen R, Chen L, Ye Y, He G, Hua K, Jarjoura D, Nakano T, Ramesh GK, Shapiro CL, Barsky SH, Gao JX: Piwil2 is expressed in various stages of breast cancers and has the potential to be used as a novel biomarker. Int J Clin Exp Pathol 2010, 3:328-337.

15. Li L, Yu C, Gao H, Li Y: Argonaute proteins: potential biomarkers for human colon cancer. BMC Cancer 2010, 10:38.

16. Anderson L, Seilhamer J: A comparison of selected mRNA and protein abundances in human liver. Electrophoresis 1997, 18:533-537.

17. Morris AR, Mukherjee N, Keene JD: Systematic analysis of posttranscriptional gene expression. Wiley Interdiscip Rev Syst Biol Med 2010, 2:162-180.

18. Taubert H, Greither T, Kaushal D, Wurl P, Bache M, Bartel F, Kehlen A, Lautenschläger C, Harris L, Kraemer K, Meye A, Kappler M, Schmidt H, Holzhausen HJ, Hauptmann S: Expression of the stem cell self-renewal gene Hiwi and risk of tumour-related death in patients with soft-tissue sarcoma. Oncogene 2007, 26:1098-1100.

19. Grochola LF, Greither T, Taubert H, Möller P, Knippschild U, Udelnow A, Henne-Bruns D, Würl P: The stem cell-associated Hiwi gene in human adenocarcinoma of the pancreas: expression and risk of tumour-related death. Br J Cancer 2008, 99:1083-1088.

20. Lee JH, Schutte D, Wulf G, Fuzesi L, Radzun HJ, Schweyer S, Engel W, Nayernia K: Stem-cell protein Piwil2 is widely expressed in tumors and inhibits apoptosis through activation of Stat $3 / \mathrm{Bcl}-\mathrm{X}(\mathrm{L})$ pathway. Hum $\mathrm{Mol}$ Genet 2006, 15:201-211.

21. Würl P, Kappler M, Meye A, Bartel F, Köhler T, Lautenschläger C, Bache M, Schmidt $\mathrm{H}$, Taubert $\mathrm{H}$ : Co-expression of survivin and TERT and risk of tumour-related death in patients with soft-tissue sarcoma. Lancet 2002, 359:943-945.

22. Krieg A, Mahotka C, Krieg T, Grabsch H, Müller W, Takeno S, Suschek CV, Heydthausen M, Gabbert HE, Gerharz CD: Expression of different survivin variants in gastric carcinomas: first clues to a role of survivin-2B in tumour progression. Br J Cancer 2002, 86:737-743.

23. Taubert $H$, Koehler T, Meye A, Bartel F, Lautenschläger C, Borchert S, Bache $M$, Schmidt $H$, Würl P: mdm2 mRNA level is a prognostic factor in soft tissue sarcoma. Mol Med 2000, 6:50-59.

24. Vora HH, Shah NG, Trivedi TI, Goswami JV, Shukla SN, Shah PM: Expression of C-Myc mRNA in squamous cell carcinoma of the tongue. J Surg Oncol 2007, 95:70-78.

25. Peiró S, Escrivà M, Puig I, Barberà MJ, Dave N, Herranz N, Larriba MJ, Takkunen M, Franci C, Munoz A, Virtanen I, Baulida J, Garcia de Herreros A: Snail1 transcriptional repressor binds to its own promoter and controls its expression. Nucleic Acids Res 2006, 34:2077-2084.

26. Aravin A, Gaidatzis D, Pfeffer S, Lagos-Quintana M, Landgraf P, lovino N, Morris P, Brownstein MJ, Kuramochi-Miyagawa S, Nakano T, Chien M, Russo JJ, Ju J, Sheridan R, Sander C, Zavolan M, Tuschl T: A novel class of small RNAs bind to MILI protein in mouse testes. Nature 2006, 442:203-207. 
27. Girard A, Sachidanandam R, Hannon GJ, Carmell MA: A germline-specific class of small RNAs binds mammalian Piwi proteins. Nature 2006, 442:199-202.

28. Lau NC, Seto AG, Kim J, Kuramochi-Miyagawa S, Nakano T, Bartel DP, Kingston RE: Characterization of the piRNA complex from rat testes. Science 2006, 313:363-367.

29. Brennecke J, Aravin AA, Stark A, Dus M, Kellis M, Sachidanandam R, Hannon GJ: Discrete small RNA-generating loci as master regulators of transposon activity in Drosophila. Cell 2007, 128:1089-1103.

30. Kalmykova Al, Klenov MS, Gvozdev VA: Argonaute protein PIWI controls mobilization of retrotransposons in the Drosophila male germline. Nucleic Acids Res 2005, 33:2052-2059.

31. Vagin W, Sigova A, Li C, Seitz H, Gvozdev V, Zamore PD: A distinct small RNA pathway silences selfish genetic elements in the germline. Science 2006, 313:320-324

32. Megosh HB, Cox DN, Campbell C, Lin H: The role of PIWI and the miRNA machinery in Drosophila germline determination. Curr Biol 2006, 16:18841894.

33. Chaudhuri PK, Walker MJ, Beattie CW, Das Gupta TK: Presence of steroid receptors in human soft tissue sarcomas of diverse histological origin. Cancer Res 1980, 40:861-865.

doi:10.1186/1471-2407-12-272

Cite this article as: Greither et al:: Expression of human Piwi-like genes is associated with prognosis for soft tissue sarcoma patients. BMC Cancer 2012 12:272.

\section{Submit your next manuscript to BioMed Central and take full advantage of:}

- Convenient online submission

- Thorough peer review

- No space constraints or color figure charges

- Immediate publication on acceptance

- Inclusion in PubMed, CAS, Scopus and Google Scholar

- Research which is freely available for redistribution 